\title{
$=-7$ usm

\section{Pais ouvintes e filhos surdos: o lugar das famílias em propostas educacionais bilíngues}

\author{
Hearing parents and deaf children: is the role of families in bilingual \\ educational proposals
}

Viviane Lameu Ribeiro

Fundação Educacional do Município de Assis

Raquel Lazzari Leite Barbosa Universidade Estadual Paulista Júlio de Mesquita Filho

Sandra Eli Sartoreto Oliveira Martins Universidade Estadual Paulista Júlio de Mesquita Filho

Recebido em 11 de outubro de 2018

Aprovado em 16 de abril de 2019

Publicado em 15 de julho de 2019

\section{RESUMO}

A partir do final do século XX, pesquisas intensificaram as discussões sobre o papel fundante da Língua de Sinais no desenvolvimento educacional da criança surda. No Brasil, a Língua Brasileira de Sinais - Libras - foi reconhecida, oficialmente, como a primeira língua da comunidade surda, e seu uso e divulgação garantidos por documentos legais que, no mesmo sentido, preveem que a educação do surdo ocorra em contexto bilíngue. As crianças surdas que nascem em lares de pais surdos interagem em Língua de Sinais, naturalmente, como os ouvintes, na língua oralauditiva. Por conseguinte, crianças surdas, filhas de pais ouvintes, enfrentam dificuldades para se relacionar com os membros da família, caso não haja oportunidade de apropriação da Língua de Sinais, no tempo adequado, o que interfere, negativamente, em seu desenvolvimento linguístico e educacional. Embora o papel da família seja claramente estabelecido em documentos legais e de orientações específicas do Ministério da Educação e da Secretaria de Educação Especial, explicitando a importância da aprendizagem desta língua pelos familiares, programas destinados a esse fim, constituem metas a serem perseguidas pelas escolas brasileiras. Nesse sentido, este estudo tem por objetivo discorrer sobre tais implicações, ampliando a discussão sobre a necessidade da oferta de ações 


\section{工 Wus entuará}

ISSN: 1984-6444 | http://dx.doi.org/10.5902/1984644435150

\section{Introdução}

Ao longo de toda história da educação dos surdos, a Língua de Sinais (LS) passou por processos de negação, contradição e reconhecimento, instaurados por variados métodos e práticas pedagógicas que, por sua vez, eram fundamentados em diferentes concepções sobre o surdo e sobre a surdez.

O período de negação corresponde ao tempo de, aproximadamente, um século - entre o final do século XIX e pouco mais de meados do século XX - em que o Oralismo foi adotado como principal abordagem para o ensino de surdos, os quais foram proibidos de usar sua própria língua nas instituições educacionais voltadas a eles, por acreditar-se que a mesma prejudicaria o seu desenvolvimento, representando um empecilho à aprendizagem da língua oral. De acordo com seus fundamentos, o pensamento só seria possível por meio da língua oral, sendo dependente desta (LACERDA, 1998; LACERDA, SANTOS, 2014).

Como os resultados da abordagem oralista não se mostraram muito satisfatórios, para a maioria dos surdos, em diferentes aspectos, ela passou a sofrer críticas crescentes, que apontavam seus insucessos naquilo a que se propunha. Assim, a partir da década de 1960, surgem estudos voltados às línguas de sinais, especialmente nos Estados Unidos, com o linguista William Stokoe, que atestou sua importância no desenvolvimento linguístico e cognitivo dos surdos, em diferentes áreas (STOKOE, 1960; MOORES, 1996).

Com base nesses estudos, nasceu, então, uma nova filosofia educacional denominada Comunicação Total, fomentada nos anos 70, e que propunha o uso de diferentes e simultâneas estratégias linguísticas baseadas na oralidade, no alfabeto manual, nos sinais e na escrita, a fim de se ensinar a língua majoritária e outros conteúdos curriculares (GÓES, 1999).

A corrente da Comunicação Total trouxe consigo, entre outros métodos e sistemas de comunicação como o Bimodalismo - caracterizado pelo emprego do português sinalizado, que orienta o uso concomitante de línguas em modalidades diferentes - o português oral (auditiva verbal) e a língua de sinais (gestovisual). Esse 


\section{N-Tism Althapga}

ISSN: 1984-6444 | http://dx.doi.org/10.5902/1984644435150

foi um período de contradição, pois, embora os sinais tenham passado a fazer parte do ambiente educacional do surdo, desempenhavam apenas um papel de muleta para a aprendizagem da língua oral (MOURA, LODI \& HARRISON, 1997).

O Bimodalismo sofreu várias críticas, pela ineficiência de seus resultados e, especialmente, por não proporcionar o uso efetivo nem da língua oral e nem da LS, que continuava a ser pesquisada e cuja apropriação já começava a ser compreendida como fundamental ao desenvolvimento dos surdos. Nasce, assim, uma nova proposta: o Bilinguismo, configurando-se um momento de reconhecimento da LS, por legitimá-la como primeira língua da comunidade surda e condição básica para o ensino da língua majoritária, considerada como segunda língua a ser aprendida, primordialmente, na modalidade escrita. O Bilinguismo, proposta atual e ainda em construção, considera a condição bilíngue e bicultural ${ }^{1}$ do surdo, garantindo o seu direito de ser ensinado em sua própria língua (UNESCO, 1954), tão reivindicado pela comunidade surda (FENEIS, 1999; THOMA; KLEIN, 2010).

Com a proposta bilíngue, a educação do surdo deixa de ser pensada com base em uma concepção clínico-terapêutica da surdez, tão difundida pelas práticas pedagógicas voltadas ao surdo ao longo dos tempos, e que se construíram, "implícita ou explicitamente, a partir das oposições normalidade/anormalidade, saúde/patologia, ouvinte/surdo, maioria/minoria, oralidade/gestualidade, etc." (SKLIAR, 2001, p. 9).

Segundo o Decreto $n^{\circ} 5.626 / 2005$, “considera-se pessoa surda aquela que, por ter perda auditiva, compreende e interage com o mundo por meio de experiências visuais, manifestando sua cultura principalmente pelo uso da Língua Brasileira de Sinais - Libras." (BRASIL, 2005, Cap. I, Art. $2^{\circ}$ ). Nessa definição, ora citada, subjaz uma concepção socioantropológica de surdez, fundamentada na compreensão de que o surdo faz parte de uma comunidade linguística, onde ele interage e se relaciona com o outro, na/pela LS. Implica considerar que esta língua possibilita à pessoa surda penetrar no orbe da cultura pela produção de discursos materializados nas relações

\footnotetext{
${ }^{1}$ Entrelaçado ao bilinguismo, ou seja, à consideração sobre a primeira (LS) e segunda língua (LP) no processo educacional de alunos surdos, conforme já explicitada, está o biculturalismo abrangido pela vivência em ambas as culturas - da comunidade ouvinte e da comunidade surda - devido às implicações entre língua e identidade cultural (FINAU, 2006) e essa diferencia intercultural precisa ser compreendida, multiculturalmente (PERLIN, 2001).
} 


\section{THEM efitha

ISSN: 1984-6444 | http://dx.doi.org/10.5902/1984644435150

dos horizontes sociais de "grupos específicos, que estabelecem sistemas específicos de ordem ao mundo [...] e a cada um deles os signos se revestem de sentidos próprios, produzidos a serviços dos interesses" desses diferentes grupos (MIOTELLO, 2010, p. 171).

Assim, contrariamente à visão hegemônica que define a surdez numa perspectiva centrada na recuperação da condição do ouvir, interessa compreender que ser e estar no mundo, necessariamente, remeterá ao entendimento de que o humano se constitui pelas experiências da linguagem, da consciência e do pensamento e que estas não se estabelecem fora dos signos sociais, mediadores das inúmeras e complexas interações sociais que, por sua vez, são mediadas pela forma e uso em que um sistema semiótico se materializa, por meio da língua gesto-visual.

Nesta direção, a palavra sinalizada instaura o meio de compreensão do outro e de si mesmo, pela alteridade na qual a diferença passa a ser orientada como um aspecto fundante da incompletude do sujeito, revelando os domínios da(s) cultura(s) do homem. A esse respeito, Strobel (2008) acrescenta que a comunidade surda é composta por surdos de todo o mundo que, diferentes de outros grupos, mesmo não habitando o mesmo local, de algum modo, estão ligados por uma maneira comum de se relacionar no mundo da vida e no mundo da cultura. Parafraseando Bakthin/ Volochínov (2004), pode-se afirmar que é nesta realidade que o mundo ético é alicerçado e determina os elementos semióticos que compreendem os signos e esses refletem e refratam essa mesma realidade em transformação que, por sua vez, dá materialidade ao conjunto de atos que moldam a cultura daqueles que se inscrevem no jogo das relações sociais de linguagem, pelo canal visual.

Conforme Pajeú (2014, p. 134),

(...) a palavra é o caminho para se atingir o humano, posto que seja o instrumento de humanização do ser, e se compreendemos o homem, compreendemos sua cultura. É pela palavra que conseguimos alcançar os modos de agir dos sujeitos, é por ela que se evidencia a beleza do diálogo continuado dos atos humanos. É a partir do mais denso penetrar no império dos signos, na palavra constituída na vida que se pode compreender os fenômenos em que se compõe a cultura se distanciando a ordem natural, posto que a arquitetônica da vida de cada sujeito se conforma por um suceder de atos concretos, singulares, únicos, distintos, uns dos outros e por isso dão feitio ao processo dialógico da interação humana pela linguagem que constitui suas esferas culturais. 


\section{N FutlaghaO}

ISSN: 1984-6444 | http://dx.doi.org/10.5902/1984644435150

Assim, assumir a existência dos modos operantes e viventes da comunidade surda, materializados no mundo da vida e no mundo da cultura dos homens, significa compreender esta última como resultante dos atos humanos e como "(...) fenômeno armado da imanência da vida, com vozes da alteridade, e não como produto objetificado" (ORTIZ, 1985 apud PAJEÚ, 2014, p. 133).

Recentemente, no Relatório sobre a Política Linguística da Educação Bilíngue - Língua Brasileira de Sinais e Língua Portuguesa, publicado em 2014, pelo Ministério da Educação - Secretaria de Educação Continuada, Alfabetização, Diversidade e Inclusão (MEC/SECADI), o Grupo de Trabalho (GT), designado pelas Portarias no 1.060/2013 e no 91/2013 do MEC/SECADI, promoveu reflexões essenciais para subsidiar a implementação da educação bilíngue - Libras e Língua Portuguesa, no Brasil (BRASIL, 2014).

No que concerne à Educação Bilíngue, o Relatório mencionado propõe a seguinte definição:

A Educação Bilíngue de surdos envolve a criação de ambientes linguísticos para a aquisição da Libras como primeira língua (L1) por crianças surdas, no tempo de desenvolvimento linguístico esperado e similar ao das crianças ouvintes, e a aquisição do português como segunda língua (L2). A Educação Bilíngue e regular, em Libras, integra as línguas envolvidas em seu currículo e não faz parte do atendimento educacional especializado. O objetivo é garantir a apropriação e a aprendizagem das línguas envolvidas como condição necessária à educação do surdo, construindo sua identidade linguística e cultural em Libras e concluir a educação básica em situação de igualdade com as crianças ouvintes e falantes do português (BRASIL, 2014, p. 6).

Desta forma, fica claro que a apropriação da Libras em idade adequada é fator determinante para a igualdade de condições entre a educação de surdos e ouvintes e o espaço escolar. De acordo com o Censo Escolar MEC/INEP de 2010 (BRASIL, 2014), de um total de 70.823 estudantes surdos ou deficientes auditivos, 52.500 estão matriculados em escolas comuns de ensino regular, perfazendo um total de $74 \%$ dos alunos em processo educacional pautado pelo modelo proposto pelas políticas da educação especial na perspectiva da Educação Inclusiva (WCEFA, 1990; UNESCO, 1994; BRASIL, 2008; 2011), segundo o qual, porém, corre-se o risco de incorrer em práticas em que a Libras é tratada como instrumento acessório à escolarização do 


\title{
Tusm efitua

ISSN: 1984-6444 | http://dx.doi.org/10.5902/1984644435150

surdo, utilizada apenas de forma complementar ao seu desenvolvimento infantil e nos anos iniciais de escolarização.

Tal fato contrapõe-se às investigações das políticas públicas dirigidas a grupos linguísticos minoritários, as quais, dentre outros aspectos, procuram romper com as situações educacionais de pouco êxito e, conforme o já citado Relatório sobre a Política Linguística da Educação Bilíngue, "com a lógica de que os surdos devem ser surdos em português por dever e em Libras por concessão" (BRASIL, 2014, p. 3).

Essa lógica de pensar e propor a escolarização implica pensar a responsabilidade do Estado, não apenas no ordenamento jurídico, mas, imprescindivelmente, na "prática de ações afirmativas em defesa da existência, valorização e difusão" da Libras (FERNANDES; MOREIRA, 2014, p. 61). Segundo as mesmas autoras, o impacto negativo central de desvios nas concepções sobre o surdo e, consequentemente, a falta de políticas voltadas para a sua condição educacional, como pertencente a grupos linguísticos minoritários, exigirá a continuidade na luta pelo direito à língua de sinais como língua materna, desde a mais tenra infância.

\begin{abstract}
Por que, então, no caso dos surdos, secundariza-se a questão prioritária do direito à Libras como língua materna nas políticas educacionais? Por que, em todos os documentos que compõem o aparato jurídico no que tange à situação dos surdos não há uma diretriz clara e objetiva que aponte estratégias que assegurem às crianças surdas o direito de aprender Libras na infância, até os cinco anos, em escolas públicas bilíngues? Sim, é verdade que em todos esses textos o português figura como segunda língua. Mas o direito a aprender o português como L2 assegura que a primeira língua será a Libras? (FERNANDES; MOREIRA, 2014, p. 63).
\end{abstract}

A concretização do que é previsto no campo educacional como locus de constituição da Libras pela criança surda e, especialmente, na orientação e participação da família composta por pais ouvintes, constituirá o foco das discussões a seguir. Posto isso, este ensaio objetiva discorrer sobre tais implicações, ampliando a discussão sobre a necessidade da oferta de ações dirigidas à família em programas educacionais bilíngues que, dentre outros aspectos, defende o direito da criança surda de interagir no mundo na/pela Libras.

Ademais, pretende-se analisar o programa norueguês Se mitt språk (See my language / Veja minha língua) como uma possível alternativa educacional, ressaltando 


\section{工 WFH entinab̧a}

ISSN: 1984-6444 | http://dx.doi.org/10.5902/1984644435150

o papel da família em propostas pautadas no bilinguismo, conforme previsto na Nota Técnica nº 05/2011, sobre a Implementação da Educação Bilíngue (BRASIL, 2011).

\section{PAIS OUVINTES DE FILHOS SURDOS: LACUNAS}

De acordo com Skliar (1997), dois aspectos contribuíram para o fortalecimento dessa nova perspectiva sobre a surdez: primeiramente, a existência da comunidade surda enquanto uma comunidade linguística que se identifica pelo uso de uma língua própria, a LS e, em segundo lugar, a comprovação científica de diferenças no desenvolvimento de filhos surdos de pais ouvintes e filhos surdos de pais surdos, em que estes apresentaram melhor desempenho em seu desenvolvimento cognitivo, acadêmico, linguístico, social e afetivo (STOKOE, 1960; MOORES, 1996).

A importância da apropriação da Língua de Sinais, comprovada pela pesquisa realizada com surdos em duas realidades diferentes, com pais ouvintes e pais surdos, leva a outra questão importante e de ordem básica: se aos surdos filhos de pais ouvintes também é importante se constituírem nesta, como sua primeira língua e o mais cedo possível, de que modo isso se dará, sendo que crescem em um ambiente em que esta não é usada da maneira como ocorre com os filhos de pais surdos?

A proporção de tal questionamento se amplia, relevando-se que mais de $95 \%$ dos surdos têm pais ouvintes, de acordo com vários estudiosos, entre eles, Lane (1992), Goldfeld (1997), Freeman, Carbin e Boese (1999), Quadros (2005), Silva, Pereira e Zanoli (2007) e Fernandes e Moreira (2014). Ademais, diferentes pesquisas no campo da educação de surdos (QUADROS, 2005) referem que as escolas não têm oportunizado o encontro entre adulto surdo e criança surda, elemento essencial e que serve de referência para que a criança surda construa sua identidade. Apesar dos avanços após a consolidação do Decreto № 5.626, de 22 de dezembro de 2005 que, regulamenta a Língua Brasileira de Sinas e orienta outras providencias sobre a escolarização dos surdos (BRASIL, 2005) no Brasil, poucos são os possuem contato com surdos mais velhos, sendo expostos a LS apenas tardiamente (MOURA, 2014; CAMPOS, 2014). 


\section{OFusm edtothăa}

ISSN: 1984-6444 | http://dx.doi.org/10.5902/1984644435150

Ainda, seguindo-se orientações legais para o processo de inclusão de alunos surdos no ensino regular, a presença de intérpretes de Língua Brasileira de Sinais Língua Portuguesa já é uma realidade em muitas escolas. Porém, muitos desses profissionais enfrentam dificuldades com surdos que não tiveram a oportunidade de se apropriar da LS, conforme descrito anteriormente.

Segundo censo realizado pelo Instituto Brasileiro de Geografia e Estatística (IBGE), em 2010 (OLIVEIRA, 2012), cerca de 9,7 milhões de brasileiros possuem deficiência auditiva ${ }^{2}$, conforme nomenclatura utilizada por esse órgão, o que representa 5,1\% da população brasileira. Deste total, cerca de 2,2 milhões possuem a deficiência auditiva severa, considerados pelo censo como os que têm muita dificuldade para ouvir (1,7 milhões) ou como surdos (344,2 mil), e 7,5 milhões apresentam alguma dificuldade auditiva. No que se refere à idade, cerca de 1 milhão de deficientes auditivos são crianças e jovens de até 19 anos. Esse último dado dá margem a um questionamento importante. Focalizando-se a relação entre o número de crianças e jovens surdos ou com deficiência auditiva (1 milhão) e o total de matriculados na educação básica (70.823), divulgado pelo Censo Escolar do mesmo ano de 2010, evidencia-se uma discrepância entre os números e a consideração provável de que muitos estejam fora da escola.

Silva, Pereira e Zanolli, ao considerar significativo o número de surdos no país, apontam que se as crianças surdas "não receberem um atendimento adequado e desenvolverem uma competência linguística, terão sérios problemas para constituírem-se como sujeitos ativos, participantes de uma sociedade." (SILVA; PEREIRA; ZANOLI, 2007, p. 1).

\footnotetext{
${ }^{2} \mathrm{O}$ termo deficiente auditivo, ainda utilizado em muitos textos oficiais, corresponde a uma concepção clínico-terapêutica da surdez, em que esta é medida e classificada de maneira a configurar variáveis intervenientes no desempenho linguístico do indivíduo. Conforme o Decreto $n^{\circ} 5.626$, "considera-se deficiência auditiva a perda bilateral, parcial ou total, de quarenta e um decibéis (dB) ou mais (...)." (BRASIL, 2005, Cap. I, Parágrafo único, p. 1). Em contrapartida, o termo surdo, conforme utilizado neste trabalho, não corresponde, exatamente, ao deficiente auditivo com perda auditiva profunda, como também é utilizado, segundo a mesma concepção, mas a uma identidade construída a partir da singularidade da experiência bilíngue e bicultural, em uma concepção socioantropólogica de surdez (BOTELHO, 2010).
} 


\section{- ussm,

ISSN: 1984-6444 | http://dx.doi.org/10.5902/1984644435150

De acordo com Góes:

A criança nasce imersa em relações sociais que se dão na linguagem. $O$ modo e as possibilidades dessa imersão são cruciais na surdez, considerando-se que é restrito ou impossível, conforme o caso, o acesso a formas de linguagem que dependam de recursos de audição. Sobretudo nas situações de surdez congênita ou precoce, em que há problemas de acesso à linguagem falada, a oportunidade de incorporação de uma língua de sinais mostra-se necessária para que sejam configuradas condições mais propícias à expansão das relações interpessoais, que constituem o funcionamento das esferas cognitiva e afetiva e fundam a construção da subjetividade (GÓES, 1999, p. 38).

A autora ressalta que limitações de ordem cognitiva ou afetiva não são inerentes à surdez, mas, sim, à falta de oportunidades oferecidas pelo grupo social para o desenvolvimento do surdo e, especialmente, para a consolidação da linguagem (GÓES, 1999).

Hoffmeister (2009) afirma que, mesmo as crianças surdas que possuem alguma audição são beneficiadas pela apropriação ${ }^{3}$ da LS, que ele chama de a língua da visão, pois esta é eficiente de tal forma a tirar proveito do processo visual do cérebro, que possui flexibilidade suficiente para reagir, tanto a estímulos visuais quanto auditivos. Dessa forma, apropriação da LS pode melhorar, inclusive, a aprendizagem da língua oral. Nesse sentido, o autor americano ressalta:

Ter a ASL [American Sign Language] ou Libras como uma abordagem de primeira língua em casa e na escola possibilita enormes benefícios. As informações podem facilmente e sem esforço fluir entre os pais e filhos e professores e alunos surdos. (HOFFMEISTER, 2009, p. 120-121; grifo nosso).

A aprendizagem da LS pelos pais e pelos filhos surdos deve ser resultante de processos interativos entre ambos, em um ambiente linguístico adequado e enriquecedor. No contexto dialógico é que os sujeitos serão capazes de constituir sentidos nessas línguas (de sinais e as línguas faladas), favorecendo a apropriação

\footnotetext{
${ }^{3} \mathrm{Na}$ ocasião do processo tradutório da obra de Hoffmeister (2009), o termo "aquisição" foi grafado como "apropriação" para discorrer sobre os processos de constituição da linguagem pelo surdo, visando a aproximar tais considerações da visão de língua assumida por Volochínov/Bakthin (2004).
} 


\title{
Tusm Eutuab̧a
}

ISSN: 1984-6444 | http://dx.doi.org/10.5902/1984644435150

da primeira língua pela criança surda, o mais precocemente possível. (HOFFMEISTER, 2009, p. 122; grifo nosso).

A Lei de Diretrizes e Bases da Educação Nacional, Lei n 9.396/96, alicerçada na Constituição Federal de 1988, explicita a importância da família para o processo educacional, em vários artigos, estabelecendo a incumbência das instituições de ensino, bem como do corpo docente, de estarem articulados com as famílias, visando integrá-las à escola e ajudando a fortalecer esses vínculos (BRASIL, 1996).

Igualmente, a Declaração de Salamanca sobre Princípios, Política e Prática em Educação Especial, documento internacional que orienta a política brasileira, demanda que os governos congregados incentivem a parceria com os pais:

\begin{abstract}
A educação de crianças com necessidades educacionais especiais é uma tarefa a ser dividida entre pais e profissionais. Uma atitude positiva da parte dos pais favorece a integração escolar e social. Pais necessitam de apoio para que possam assumir seus papéis de pais de uma criança com necessidades especiais. O papel das famílias e dos pais deveria ser aprimorado através da provisão de informação necessária em linguagem clara e simples; ou enfoque na urgência de informação e de treinamento em habilidades paternas constitui uma tarefa importante em culturas onde a tradição de escolarização seja pouca. (UNESCO, 1994, p. 13-14; grifos meus).
\end{abstract}

Documentos orientadores do Ministério da Educação e Cultura (MEC), por meio da Secretaria de Educação Especial - SEESP (BRASIL, 2004, 2006) se referem à importância e papel da família no desenvolvimento do educando com necessidades educacionais especiais.

Segundo o material Saberes e práticas da inclusão relacionado à surdez (BRASIL, 2006), muitos pais acabam por aprender o pigdin 4 , como única forma de dialogar com os filhos surdos, resultando em uma prática inapropriada ao processo de desenvolvimento da LS. Contrária a esta condição, propostas bilíngues defendem garantir a expansão das relações interacionais e de constituição da L1 com parceiros mais eficientes nesta língua (L1) - no caso, surdos usuários deste sistema. Nesta

\footnotetext{
${ }^{4}$ Forma linguística resultante do contato entre duas línguas, que utiliza geralmente a estrutura de uma língua e o vocabulário de outra. No caso do contato entre a língua portuguesa e a Libras, são formulações frasais em língua portuguesa utilizando simultaneamente os sinais como apoio à comunicação (BRASIL, 2006, p. 51).
} 


\section{Tusm Eutioará}

ISSN: 1984-6444 | http://dx.doi.org/10.5902/1984644435150

direção, recomenda-se aos pais ouvintes aprender a LS o mais cedo possível, favorecendo o desenvolvimento emocional, linguístico e afetivo do seu filho (BRASIL, 2006, p. 51).

Em artigo relacionado à sua pesquisa de doutorado sobre o atendimento às famílias de crianças surdas, no Centro de Estudos e Pesquisas em reabilitação (CEPRE/FCM/UNICAMP), Silva et al (2007) observa que os pais são fortemente influenciados pela forma como eles próprios percebem as funções do aparelho auditivo e pela informação recebida, atitude e qualidade de aconselhamento do profissional que os atendeu, normalmente profissional médico e audiológico e/ou fonoaudiólogo, por serem os primeiros que diagnosticam, identificam e aconselham os pais (SILVA; PEREIRA; ZANOLI, 2007).

Hoffmeister salienta que há uma visão patológica dominante nesses profissionais que atendem os pais, logo após o diagnóstico da perda de audição, e que resulta como influência negativa, em que os surdos acabam por serem compreendidos como um problema (HOFFMEISTER, 2009).

Nesse sentido, programas e projetos para pais de crianças surdas se tornam fundamentais, em um trabalho pautado sob uma concepção socioantropológica de surdez, que venha a romper com possíveis barreiras que os impeçam de compreender, a partir desse viés, o que é ser surdo e a importância da LS para vida do filho surdo e da própria família, para seu desenvolvimento e emancipação. Barreiras essas, marcadas por mitos relacionados a essa língua (QUADROS, 1997) e pela concepção clínico-terapêutica da surdez, na qual se basearam ações voltadas para os surdos, ao longo dos tempos, e que ainda se refletem e são fortalecidas pelo ideal de etnocentrismo vigente, que nega e rejeita as diferenças, baseado em um padrão único, em um ideal monolítico de cultura (MACHADO, 2008).

Ações relacionadas à divulgação da LS, como o programa nacional "Interiorizando Libras" estão mormente voltadas à formação continuada de professores e instrutores, ouvintes e surdos, não abarcando a questão familiar (BRASIL, 2011). Apesar disso posto, bem como de todos os questionamentos acima expostos, sabe-se que muito há que se fazer para garantir o direito à educação bilíngue para surdos, no qual a atenção à família se constitui como um ato concreto 


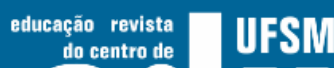 Gutrathá}

ISSN: 1984-6444 | http://dx.doi.org/10.5902/1984644435150

na seara das discussões que arrogam a língua que lhes é própria. Por conseguinte, apresenta-se, a seguir, o programa norueguês Se mitt språk (See my language / Veja minha língua) que, apesar de fazer parte de uma realidade bastante diferente, sendo a Noruega considerada como o país com o melhor Índice de Desenvolvimento Humano (IDH) do mundo, pode se constituir como um ponto de apoio e de escuta àqueles que buscam alterar essa realidade e, consequentemente, como importante referência para futuras e urgentes ações nesse sentido.

\section{PROGRAMA SE MITT SPRÅK COMO (POSSÍVEL) REFERÊNCIA PARA FUTURAS AÇÕES}

Em visita à Noruega, entre os meses de maio e abril de 2009, por meio do programa GSE - Group Study Exchange (Intercâmbio de Grupos de Estudo), patrocinado pela Fundação Rotária do Rotary International, foi possível observar, registrar e analisar, por meio de diário de campo (BOGDAN; BIKLEN, 1994; MACEDO, 2010), bem como por materiais de divulgação e relatório sobre o programa (LILTVED, 2002; 2006), a educação dos surdos, tanto no ambiente inclusivo quanto em escolas especiais, os recursos tecnológicos na área da surdez, bem como o uso e difusão da Língua de Sinais Norueguesa (NSL).

O referido programa é voltado para profissionais de diferentes áreas e objetiva o conhecimento de técnicas e metodologias ligadas às profissões dos participantes, além de vivência da cultura do país de destino, sendo que o distrito rotariano anfitrião recebe os currículos, antecipadamente, para organizar visitas que sejam relevantes e cumpram com os objetivos do intercâmbio, que tem duração de quatro a seis semanas.

Em 1992, foi estabelecido um sistema nacional de apoio a crianças e jovens com deficiência no referido país, a fim de auxiliar as famílias, as escolas locais e as autoridades municipais nos seus esforços para a inclusão educacional (HYDE, OHNA \& HJULSTADT, 2005). Trata-se de um programa que compreende a organização de centros de recursos financiados pelo estado e de centros associados financiados por meios independentes. Esses diferentes centros de recursos oferecem supervisão e 


\section{FESH

ISSN: 1984-6444 | http://dx.doi.org/10.5902/1984644435150

orientação individuais para crianças e suas famílias, bem como programas para municípios e escolas locais, dos quais interessa destacar os que apoiam os familiares dos estudantes surdos.

O pesquisador finlandês Makku Jokinen (2009), em seu artigo sobre a educação dos surdos nos países nórdicos, destaca ações pioneiras destes quanto à educação bilíngue, apontando o trabalho realizado com as famílias das crianças surdas, especificamente na Noruega e na Suécia, como um indicador da preocupação de que a LS seja utilizada por eles, o mais cedo possível. O autor ressalta que as práticas desenvolvidas nos países nórdicos, sua estrutura política, legislativa e educacional difere dos demais países, em todo o mundo.

Embora, na Suécia, cada vez mais pais de crianças surdas compreendam a importância da SSL (Swedish Sign Language), apenas a Noruega oferece um programa estruturado de treinamento a pais ouvintes de filhos surdos (JOKINEN, 2009).

O referido programa se destacou por seu caráter inédito e pela coerência com os propósitos do sistema norueguês, no que se refere ao envolvimento das famílias e a compreensão da imprescindibilidade da apropriação da LS como a primeira língua e sua importância para o pleno desenvolvimento e desempenho acadêmico dos estudantes surdos.

Conforme Jokinen:

É importante que as crianças vivenciem experiências exatamente como qualquer outra criança ouvinte da mesma idade, tanto linguisticamente, como em outros aspectos. Os pais deveriam receber oportunidades de aprender tanto quanto possível a língua de sinais logo que descobrem que a criança é surda. (JOKINEN, 2009, p. 119).

O programa, denominado Se Mitt Språk, tem sido oferecido desde 1996 e consiste no treinamento do uso da NSL e na discussão de temas relacionados à surdez e à condição de pais de filhos surdos. O principal propósito do programa é ensinar aos pais como alcançar uma comunicação eficiente com seu filho (LILTVED, 2002). 


\section{Fusm eltoargá}

ISSN: 1984-6444 | http://dx.doi.org/10.5902/1984644435150

Magne Bentzen, então líder do Comitê Nacional de Trabalho de Pais da Noruega (Parents' National Working Committee) e pai de uma filha surda que tinha 10 anos de idade à época, ressalta:

Este projeto é uma das iniciativas mais claramente positivas tomadas para pais de filhos surdos ou com dificuldades de audição. Um importante efeito do ensino da língua de sinais é que ele permite que pais encontrem outros pais na mesma situação. (...) Eu vejo uma nova geração de surdos com ótima autoconfiança, e eu acredito que a principal razão é que nós temos trazido a língua de sinais para dentro das escolas e lares tão fortemente. (LILTVED, 2002, p. 8; tradução nossa).

De acordo com material coletado em visitas a dois centros de recursos, sendo uma visita realizada no centro de recursos localizado no condado de Rogaland, em Stavanger, e outra, no condado de Hordaland, em Bergen - material informativo e relatório do programa (LILTVED, 2002) -, o treinamento é gratuito e compreende 40 (quarenta) semanas de aprendizagem em LS para pais ou responsáveis ouvintes, organizados ao longo dos 16 (dezesseis) primeiros anos de vida dos filhos surdos, sendo que 33 (trinta e três) semanas são geridas pelos centros nacionais de educação especial para surdos (centros de recursos) e as demais acontecem na $\AA$ folkehøyskole, uma escola de ensino médio e centro de recursos para surdos do município de Ål, situado em Hallingdal, entre Oslo e Bergen. Os centros de recursos estão localizados em diferentes regiões do país.

O quadro abaixo ilustra a maneira como os módulos são distribuídos.

Quadro 1 - Distribuição dos módulos do programa Se Mitt Språk

\begin{tabular}{|l|c|c|c|}
\hline $\begin{array}{l}\text { Idade do(a) } \\
\text { Filho(a) surdo(a) }\end{array}$ & $\begin{array}{l}\text { Número de } \\
\text { semanas por } \\
\text { ano }\end{array}$ & $\begin{array}{l}\text { Número total de } \\
\text { semanas }\end{array}$ & $\begin{array}{l}\text { Número de } \\
\text { semanas na } \\
\text { faculdade de Ål }\end{array}$ \\
\hline $1-3$ anos & 4 & 12 & 1 \\
\hline $4-5$ anos & 3 & 6 & 2 \\
\hline $6-9$ anos & 2 & 8 & 1 \\
\hline $10-11$ anos & 3 & 6 & 1 \\
\hline $12-16$ anos & 2 & 8 & \\
\hline
\end{tabular}

Fonte: traduzido e adaptado de LILTVED, 2002, p. 12. 


\section{THEM Eutuab̧a}

ISSN: 1984-6444 | http://dx.doi.org/10.5902/1984644435150

Conforme se pode observar, por meio dos dados da tabela, quase metade dos módulos do programa se realizam quando a criança surda ainda está em fase préescolar.

Tal fato coaduna com diferentes estudos de linguagem na área da surdez, ao passo que defendem a necessidade da oferta de programas educacionais que privilegiem o desenvolvimento da LS pela criança surda em tenra idade, como no caso do estudo destacado (LILTVED, 2002). Ao ler sobre o programa em questão, considera-se oportuno retomar, brevemente, os estudos de Freitas (1994), a quem comungam as ideias de Bakhtin e Vygosty, sobre o papel da linguagem no desenvolvimento da consciência humana, pressuposto este fundamental para compreender os processos de apropriação da LS, pela criança surda.

Ao analisar as obras dos autores, Freitas (1994) lembra que ambos constroem teorias diferentes - Bakhtin, a construção de uma concepção histórica e social da linguagem, e Vygotsky, a formulação de uma psicologia historicamente fundamentada - porém, pode-se dizer que muitos são os pontos de encontro entre suas ideias. ${ }^{5} \mathrm{Em}$ outros termos, os autores defendem que o homem é um ser histórico e produto de um conjunto de relações sociais, a partir das quais modela-se a mente e promove-se o psiquismo. Tal premissa nasce de uma perspectiva semiótica, na qual o signo é considerado um produto social, tendo a função geradora e organizadora dos processos psicológicos superiores. Assim, a mediação semiótica do psiquismo é colocada como um ponto de partida nos trabalhos de Bakhtin e Vygosty, do qual decorrem outros aspectos comuns: a constituição da consciência pela interiorização da linguagem, a linguagem interior como trama semiótica da consciência, o papel do outro e do diálogo nesse processo de interiorização, a intervenção crucial do contexto. Ambos defendem que a consciência é engendrada no social, a partir das relações que

\footnotetext{
5 A autora (Freitas,1994) lembra que as semelhanças dos constructos dos autores sobre os fundamentos da linguagem está ligada a dois pontos básicos: o método dialético e a sua visão de ciências humanas. A esse respeito, lembra que partindo da dialética - Vygotsky e Bakhtin, construíram uma visão totalizante, não fragmentada da realidade, uma perspectiva que, enraizada na história, compreende o homem como um conjunto de relações sociais. Contrários às dicotomias presentes nas concepções de linguagem e de psicologia de seu tempo, por oscilarem entre os polos subjetivo e o objetivo, arquitetaram suas teorias num entrelaçamento de sujeito e objeto, propondo uma síntese dialética imersa na cultura e na história.
} 


\section{Tusm elitrabá}

ISSN: 1984-6444 | http://dx.doi.org/10.5902/1984644435150

os homens estabelecem entre si, por meio de uma atividade sígnica e, portanto, pela mediação da linguagem.

Tomada pelos pressupostos de Vygotsky e Bakhtin, Freitas (1994) situa que o homem ascende à sua humanidade, quando se transforma de ser biológico em ser sócio-histórico a partir do momento em que reflete a realidade objetiva de forma mediada, utilizando instrumentos psicológicos, os signos, na interação com os outros. Para o primeiro (VYGOTSKY, 1989; 1995; 2001), as funções mentais elementares se transformam, qualitativamente, em funções mentais superiores pela utilização da linguagem adquirida no contato social. Nesta concepção, a consciência é o resultado dos próprios signos. Eles permitem realizar transformações no outro e no meio externo, por meio do outro, como também a regulação da própria conduta. Assim, os signos realizam a mediação do homem com os outros e consigo mesmo, constituindose na única forma adequada para investigar a consciência humana. Já, para o segundo (BAKHTIN, 1992), os fundamentos da consciência não são fisiológicos nem biológicos, mas, sim, sociológicos, não podendo ser reduzidos a processos internos. Ela se constitui no social, via linguagem. Sem o material semiótico, a consciência resulta em ficção. Além dos signos, há em nossa consciência imagens de forma, cores, odores, sabores, as quais também só adquirem um caráter significativo, só se transformam numa sensorialidade humana, pela linguagem. A matéria do psiquismo é, portanto, a semiótica, e sua realidade é a realidade do signo, sendo este social.

Freitas (1994) se baseia nos constructos teóricos da filosofia da linguagem de Bakhtin, segundo os quais o papel do signo, na consciência humana, é um fenômeno do exterior, criado pelo homem, que emerge no terreno interindividual e cuja significação se produz na dinâmica das interlocuções, de forma que a consciência individual nada pode explicar, a não ser a partir do meio ideológico e social, sendo, portanto, um fato socioideológico. Parafraseando suas obras, a autora afirma que o processo de constituição da linguagem ocorre durante a assimilação da experiência alheia, por meio da mediação semiótica. Em outros termos, pelo uso da língua. Não existe signo interno na consciência que não tenha sido engendrado na trama ideológico-semiótica da sociedade. 


\section{FUsy eltoargá}

ISSN: 1984-6444 | http://dx.doi.org/10.5902/1984644435150

Conforme exposto, ao destacar a linguagem como fundante dos processos de desenvolvimento das funções psicológicas superiores da criança surda - com destaque ao desenvolvimento da linguagem, em cujo processo a LS ocupa um papel determinante - o programa evidencia esforços para que o ensino desta seja uma prática efetiva, trazendo benefícios aos lares das crianças surdas, filhas de pais ouvintes, contexto gerador das tensões deste texto. Colocar pais e familiares no centro das estratégias formativas dos ambientes educacionais parece ser um caminho promissor na conformação de uma rede relacional entre os que vivenciam essa situação, deflagrando um senso de comunidade, em que podem trocar experiências e se fortalecer, mutuamente, como beneficiários do programa destacado (LILTVED, 2002).

O programa de ensino da LS na Ål folkehøyskole é oferecido a toda a família e financiado pela administração de segurança nacional (National Insurance Administration), sendo que também há um curso de LS específico para irmãos ouvintes, de 8 (oito) semanas, cuja oferta pode ser ampliada durante as 7 (sete) semanas de estada dos pais em Ål. Tal período é reconhecido como educação formal, não sendo registrada ausência na escola em que frequentam, referente a esse período.

O Estado, neste contexto, assume sua efetivação a partir do aporte de transporte e alojamento, durante as semanas em que se realiza o programa, sendo que durante a sua realização, os pais têm direito a uma licença do trabalho, recebendo um benefício (abono) equivalente ao auxílio doença do país e subsídio para despesas com material, que deve ser pago por eles.

Ainda cumpre esclarecer que, se desejarem, os pais podem deixar os filhos, por meio período, na pré-escola e/ou escola dos centros de recursos. No treinamento em Ål, também são possíveis arranjos para atender as crianças surdas e seus irmãos, independentemente de suas idades.

A participação dos pais tem início por meio de pedido à autoridade educacional local que, por sua vez, encaminha-o ao centro de recursos regional, através de um formulário especial para requisição de serviços do sistema nacional de apoio à 


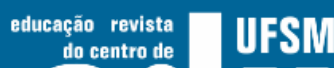 Gutrathá}

ISSN: 1984-6444 | http://dx.doi.org/10.5902/1984644435150

educação especial. Os formulários podem ser enviados a qualquer momento, durante o ano (LILTVED, 2006).

Três grupos alvo são considerados para o programa:

- Pais que, recentemente, descobrem a surdez do filho e são direcionados ao programa geral, iniciando pelo primeiro módulo, que ocorre no período de outono.

- Pais de filhos surdos nascidos antes do ano de 1992, aos quais sãos oferecidas 2 (duas) semanas adaptadas por ano, até que seus filhos completem dezesseis anos.

- Pais de crianças surdas com deficiências múltiplas que, além do programa geral, recebem um serviço diferenciado e/ou adaptado podendo recorrer a um centro de recursos específico. Contudo, tais pais podem optar por cursar o programa de ensino da LS em um centro de sua região, caso prefiram.

Dentro do plano de curso de Se Mitt Språk, constam 900 (novecentas) horas para aprendizagem e prática da LS e 100 (cem) horas para o trabalho e discussão com diferentes temas, como informações sobre a estrutura pública de apoio, os direitos dos surdos e as opções pedagógicas disponíveis, identidade bilíngue e bicultural e outros tópicos relevantes: comunicação e linguagem, família e sociedade, cultura e história, audiologia, e assuntos relacionados à vida escolar (LILTVED, 2006).

As aulas voltadas para a aprendizagem da LS incluem a cultura e a história da comunidade surda. O método utilizado para o ensino da LS é consideravelmente firmado em um modelo indutivo e comunicativo de aprendizagem, em que esta ocorre por meio de experiências práticas e concretas, com base em diferentes contextos de uso da língua (LILTVED, 2002).

Em visita realizada em Statped Vest (Serviço de Educação Especial do Estado), no centro de recursos localizado em Stavanger, ao dialogar com membros da equipe gestora e professores surdos e ouvintes, evidenciou-se uma prática de ensino dinâmica e centrada no uso da LS com apoio e aplicação de recursos variados, como jogos e meios tecnológicos (cabines de computadores com webcam etc.). 


\section{$-1$ FutlaghaO}

ISSN: 1984-6444 | http://dx.doi.org/10.5902/1984644435150

Entre os materiais pedagógicos ${ }^{6}$ utilizados para o ensino da LS, além dos

livros e dicionário, destacam-se os voltados para a educação a distância, favorecendo o autoestudo e a complementação ao currículo do programa, bem como materiais desenvolvidos pelo centro de recursos de Møller, como vídeos e CD-ROMs (LILTVED, 2002, 2006).

Os materiais didáticos são adquiridos pelos familiares e interessados, por valores que visam a custear a produção dos recursos e/ou materiais destinados ao desenvolvimento das atividades propostas.

Para a melhor gestão do programa, desde 1997, foi formado um comitê nacional para informação e coordenação, dirigido por um coordenador nacional e composto pelos líderes ou delegados de cada centro de ensino de LS. Informes descritos no relatório de Liltved (2002) referem que, desde a sua criação, em 1996, até o ano de 2001, 994 (novecentos e noventa e quatro) pais frequentaram o programa ora mencionado. Este pode ser compreendido como um número considerável, tendo por base as estatísticas da população surda na Noruega. De acordo com o a biblioteca online da universidade americana Gallaudet, instituição que é referência no tocante à educação de surdos, em 1986 foi reportada a existência de mais de 4.000 surdos/ deficientes auditivos no país nórdico e, em 2010, cerca de 5.000 (GALLAUDET, 2017).

\footnotetext{
${ }^{6}$ See my language - livro introdutório à NSL; Do you remember? - ilustração em vídeo do See my language; Traduções da NSL para o norueguês dos textos contidos em Do you remember?; You see! - CD Rom com conteúdo do livro See my language e do vídeo Do you remember?; Adult education and linguistics - introdução para os conselheiros em LS no ensino para os pais ouvintes; Sing language for parentes - compêndio do curso; Practice makes perfect - revisão em vídeo dos 9 (nove) primeiros módulos; The four seasons - vídeos; Tell it by vídeo - O uso da câmera de vídeo no treinamento da LS; The memorable days of life - contendo programa 1 (crianças e jovens) e programa 2 (casamento e funeral); Instruction book to the language book - revisão em LS do livro Language Book para o conselheiro em LS; TegnRom 1, 2, 3 e 4-programa de computador com seis atividades para surdos e duas para seus pais, em cada CD Rom; TegnStart - programa interativo com diferentes atividades para aprendizagem intensiva da língua, em CD Rom; Norwegian Sign Dictionary - dicionário em CD Rom; Let you hands speak - dicionário com milhares de sinais relacionados à vida diária e temas de interesse entre crianças e adolescentes (LILTVED, 2002, 2006).
} 


\section{Fism elitrabá}

ISSN: 1984-6444 | http://dx.doi.org/10.5902/1984644435150

\section{Conclusão}

Após longos anos de intensa luta pela conscientização e reconhecimento da LS, pode-se dizer que houve avanços consideráveis nessa direção, tanto pela maior abertura proveniente de novo contexto, iniciado ao final do século XX, pelo movimento mundial de valorização das diferenças e inclusão social, como também de pesquisas que trouxeram, em caráter científico, conhecimentos e esclarecimentos acerca dessa língua quanto à sua estrutura gramatical própria, aos parâmetros universais linguísticos nela presentes como nas demais línguas, às implicações de seu uso em relação ao desenvolvimento da pessoa surda e desdobramentos culturais, bem como ao fortalecimento do bilinguismo como base para a educação dos surdos.

No Brasil, tais avanços estão expressos em documentos nacionais que legitimam a língua, seu uso e papel na educação dos surdos. Porém, em termos práticos, lacunas se apresentam para a concretização dos discursos legais - mesmo estando esses ainda aquém do reivindicado pelos movimentos surdos. Entre tais lacunas, a diferença entre o número de crianças e jovens surdos ou deficientes auditivos apurado pelas estatísticas e o número de efetivamente matriculados na educação básica, evidenciando que muitos ainda estão fora da escola. Ademais, a pouca expressividade de ações que possibilitem o acesso efetivo e em tempo adequado das crianças surdas à LS, acaba por comprometer o processo de escolarização dos estudantes surdos que, inseridos em sala de aula comum - desde a tenra idade, com a presença de intérpretes de Libras, sem que ambos tenham fluência nesta língua, acaba por reforçar a lógica da exclusão e dos atrasos de diversas ordens em seu desenvolvimento, apesar das comprovações científicas já postuladas sobre tais consequências, conforme demonstrados por diferentes estudos que retrataram esta temática (LODI, 2013; 2014; FERNANDES, MOREIRA, 2014).

Do mesmo modo, embora o papel da família se faça claro e estabelecido, tanto em documentos legais quanto em orientações específicas do Ministério da Educação e da Secretaria de Educação Especial em relação à educação dos surdos, inclusive, versando sobre a importância de que pais ouvintes aprendam a LS para contribuir no desenvolvimento de seus filhos, nota-se a inexistência de programas governamentais, 


\section{FESH eltoargá}

ISSN: 1984-6444 | http://dx.doi.org/10.5902/1984644435150

de âmbito nacional, sistematizados e dirigidos ao ensino desta língua para os familiares, constatadas pela sondagem e leitura de documentos disponíveis nos portais do governo federal (www.brasil.gov.br) e Ministério da Educação (www.portal.mec.gov.br; www.portal.inep.gov.br), realizada no período de março/julho de 2018. A partir desta sondagem preliminar, o ensaio conclama considerar como as políticas públicas federais tem orientado os sistemas de ensino garantir possibilidades concretas aos surdos se constituírem em LS? Em outros termos, que ações e/ou programas tem sido recomentados aos familiares de apropriação e uso da LS?

Nesse sentido e, especialmente, considerando-se o papel primordial e insubstituível da linguagem, conforme os estudos de Vygotsky e Bakhtin, embora se deva considerar as acentuadas diferenças entre o Brasil e a Noruega, principalmente em relação à economia, educação e densidade populacional, o programa norueguês Se Mitt Språk pode ser considerado como relevante experiência e referência na ampliação do envolvimento da família em propostas pautadas na educação bilíngue, que valorizem a compreensão da surdez como diferença e, não, deficiência. Discorrer sobre a surdez nessa perspectiva remeterá possibilitar ao surdo enunciar e ser enunciado em LS, como primeira língua, concebendo o papel da família como o elemento fulcral dos processos constitutivos da linguagem, em seu desenvolvimento, na primeira infância.

\section{Referências}

BAKHTIN, Mikhael Mikhailovitch. Estética da criação verbal. Tradução de Michel Lahud e Yara Frateschi Vieira. São Paulo: Hucitec, 1992.

BAKHTIN, Mikhael Mikhailovitch / VOLOCHÍNOV, Valentín Nikoláievitch. Marxismo e filosofia da linguagem. Tradução de Michel Lahud e Yara Frateschi Vieira. São Paulo: Hucitec, 2004.

BOGDAN, Robert C.; BIKLEN, Sari, K. Investigacão qualitativa em educação. Tradução Maria J. Alvarez, Sara Bahia dos Santos e Telmo M. Baptista. Porto, Portugal: Porto Editora, LDA, 1994. 


\section{Fisw Eutuab̧a}

ISSN: 1984-6444 | http://dx.doi.org/10.5902/1984644435150

PAJEÚ, Hélio Márcio. A palavra é a ponte para se compreender a cultura pela alteridade. In Grupo de Estudos dos Gêneros do Discurso (GEGe) Palavra e contrapalavras: constituindo o sujeito em alter-ção. Pedro \& João: São carlos, 2014.

PERLIN, Gladis. Identidades surdas. In.: SKLIAR, Carlos (Org.). A surdez: um olhar sobre as diferenças. 2. ed. Porto Alegre: Mediação, 2001.

QUADROS, Ronice Müller de. Educação e surdos: aquisição de linguagem. Porto Alegre: Artmed, 1997.

QUADROS, Ronice Müller de. O bi do bilinguismo na educação de surdos. In: QUADROS, Ronice Müller de. Surdez e bilinguismo. v. 1.1 ed. Porto Alegre: Editora Mediação, 2005, v.1, p. 26-36.

SILVA, Angélica Bronzatto de Paiva; PEREIRA, Maria Cristina da Cunha; ZANOLI, Maria de Lurdes. Mães Ouvintes com Filhos Surdos: Concepção de Surdez e Escolha da Modalidade de Linguagem. Psicologia: Teoria e Pesquisa, v. 23, n. 3, p. 279-286, jul-set. 2007. Disponível em http://www.scielo.br/pdf/ptp/v23n3/ a06v23n3.pdf . Acesso em: 28 abr. 2017.

SKLIAR, Carlos (Org.). Educação \& exclusão: abordagens sócio-antropológicas em educação especial. Porto Alegre: Editora Mediação, 1997.

SKLIAR, Carlos (Org.). A surdez: um olhar sobre as diferenças. 2. ed. Porto Alegre: Mediação, 2001.

STATPED. Glossary of hearing-related terms. Norwegian Deaf Association. Norway: Skådalen Resource Centre. Jan. 2007. Disponível em: http://www.statped.no/globalassets/fagomrader/horsel/dokumenter/glossary-ofhearing-related-terms.pdf Acesso em 27 Fev. 2017.

STOKOE, Willian. Sign language structure: an outline of the visual communication systems of the american deaf. Studies linguistics, vol. 8, 1960.

STROBEL, Karin Lilian. As imagens do outro sobre a cultura surda. Florianópolis: Editora UFSC, 2008.

STROBEL, Karin Lilian. Surdos: vestígios culturais não registrados na história. Tese de doutorado em educação, na linha de pesquisa Educação e Processos Inclusivos. Florianópolis, Editora UFSC, 2008.

THOMA, Adriana da Silva; KLEIN, Madalena. Experiências educacionais, movimentos e lutas surdas como condições de possibilidade para uma educação de surdos no Brasil. Cadernos de Educação (UFPel), v. 1, p. 107-131, 2010.

UNESCO. Las lenguas vernáculas en la enseñanza. Paris: Ediciones de la Unesco, 1954. 


\section{工 WFH Gutrathá}

ISSN: 1984-6444 | http://dx.doi.org/10.5902/1984644435150

UNESCO. Ministério da Educação e Ciência da Espanha. Relatório final: Conferência mundial sobre necessidades educacionais especiais: acesso e qualidade. Salamanca: UNESCO, 1994.

VYGOTSKY, Lev Semyonovich. Fundamentos de defectologia. Havana: Pueblo y Educación, 1989.

VYGOTSKI, Lev Semyonovich. Obras escogidas. v. II. Madrid: Visor, 1995.

VIGOTSKI, Lev Semyonovich. A construção do pensamento e da linguagem. Tradução Paulo Bezerra. São Paulo: Martins fontes, 2001.

WCEFA - CONFERÊNCIA MUNDIAL DE EDUCAÇÃO PARA TODOS. Declaração mundial sobre educação para todos e plano de ação para satisfazer as necessidades básicas de aprendizagem. Jomtien, Tailândia. UNICEF, 1990.

\section{Correspondência}

Viviane Lameu Ribeiro - Professora titular na Fundação Educacional do Município de Assis - FEMA e na Universidade Paulista - UNIP.

Raquel Lazzari Leite Barbosa - Professora adjunta na Faculdade de Ciências e LetrasUNESP-Assis/SP e Professora Orientadora do Programa de Pós-Graduação em Educação da Faculdade de Filosofia e Ciências da Universidade Estadual Paulista, Campus de Marília.

Sandra Eli Sartoreto Oliveira Martins - Professora assistente doutora do Departamento de Educação Especial e do Programa de Pós-Graduação em Educação, da Faculdade de Filosofia e Ciências da Universidade Estadual Paulista, Campus de Marília.

Universidade Estadual Paulista - Faculdade de Ciências e Letras - Câmpus de Assis. Av. Dom Antonio, 2100 - Parque Universitário - CEP 19806-900. Assis, São Paulo, Brasil.

E-mail: vivilameur@gmail.com - raqueleite@uol.com.br - sandra.sartoreto@gmail.com

iD ORCID: http://orcid.org/0000-0002-4247-1447

This work is licensed under a Creative Commons Attribution-NonCommercial 4.0 International (CC BY-NC 4.0) 